\title{
ANÁLISIS COMPARATIVO DEL RENDIMIENTO DE UNA ESTRATEGIA DE CONTROL TRADICIONAL PID CONTRA LAS ESTRATEGIAS DE CONTROL MODO DESLIZANTE DE SEGUNDO ORDEN EN UN GENERADOR SINCRÓNICO
}

\section{COMPARATIVE ANALYSIS OF PERFORMANCE OF A PID TRADITIONAL CONTROL STRATEGY VS SECOND ORDER SLIDING MODE CONTROL STRATEGIES ON A SYNCHRONIC GENERATOR.}

PhD. Manuel ivan Castellanos Garcia *'MSc. Jorge Arturo Pérez Venzor*, MSc. Rubén Enrique Rojas Rangel*, MSc. David García Chaparro*, MSc. Abdi Delgado Salido*, MSc. Hector Loya Caraveo*,

* Universidad Autónoma de Ciudad Juárez, Departemento de Ingenieria Electrica. Avenida del Charro numero 450 norte, Ciudad Juarez, Chihuahua, Mexico.

Teléfono y Fax :6566883800.

E-mail: \{mcastell, jorperez\}@uacj.mx

Resumen: Se realiza un análisis de rendimiento para comparar el comportamiento del control PID tradicional frente a las estrategias de control de modo deslizante de segundo orden aplicadas a un generador sincrónico sujeto a perturbaciones en la carga.

Palabras clave: Sliding mode control, Twisting, Super-Twisting.

Abstract: A performance analysis is made to compare the behavior of the traditional PID control vs. second order sliding mode control strategies applied to a synchronic generator subject to disturbances on load.

Keywords: PID, Sliding mode control, Twisting, Super-Twisting.

\section{INTRODUCTION}

Electric energy demand is constantly growing as human needs. Those needs are related to a major comfort derived from evolution of his live style. Get electric energy for consume requires to meet several technical requirements, one of the most important requirements is the voltage level which usually should be maintained to certain level depending of the specific needs. A feedback control system is used to meet that technical requirement in order to guarantee that the voltage level will not vary, even the electric energy generator system be subject to disturbances.

Those disturbances are usually in the case of a synchronic generator due to speed change on the rotor, changes on demand of electric energy coming form load, and change on system parameters (generator or load) related to heat or wear. 


\section{SYSTEM MATEMATICAL MODEL}

Synchronous generators can be modeled on two ways one is the dynamic model, and the other is the static model. In order to predict system behavior MatlabSimulink is used to simulate system response under different operating conditions. Matlab-Simulink requires knowing the static model which can be obtained according to : (Stephen J. Chapman, 1996; Salvador Campos et al., 2005). Parameters required for simulation are obtained for a commercial Chevrolet vehicle alternator (in order to perform this analysis the self constructed control system contained in the alternator is previously removed so the different control strategies can be implemented) which is used as synchronous generator with parameters as follows (table1):

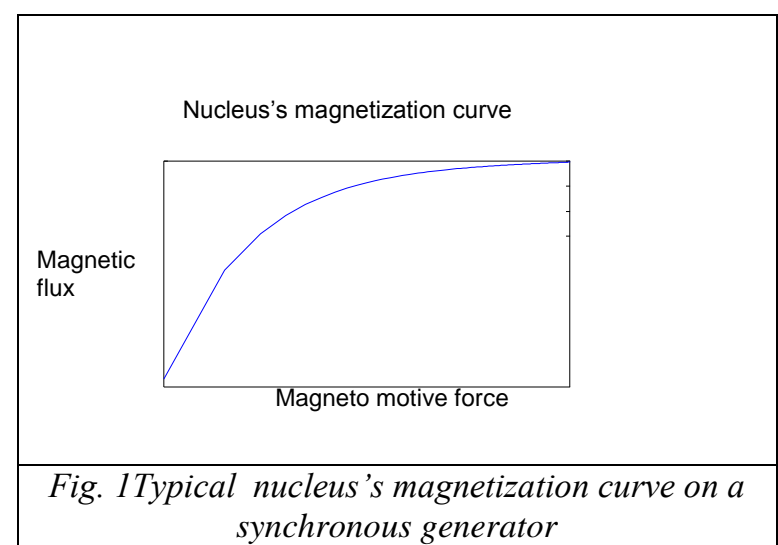

\begin{tabular}{|c|c|}
\hline \multicolumn{2}{|c|}{ table 1 parameters } \\
\hline Rotor type & Salient pole. \\
\hline Nominal power & 400VA. \\
\hline Line to line voltage & $6.4126 \mathrm{~V}$ \\
\hline Nominal frequency & $332.5 \mathrm{~Hz}$. \\
\hline Nominal field current & 8.0Amp. \\
\hline Stator resistance & $R_{S}(\Omega)=0.091 \Omega$ \\
\hline Leakage inductance & $L_{l}(H)=3.11 \times 10^{-5} H$ \\
\hline Direct axis inductance & $L_{d}(H) \_4.55 \times 10^{-5} H$ \\
\hline Quadrate axis inductance & $L_{q}(H) \_13 \times 10^{-5} H$ \\
\hline $\begin{array}{l}\text { Field resistance } \\
\text { resistance }\end{array}$ & $R_{f d}(\Omega)=4.0 \Omega$ \\
\hline Field leakage inductance & $L_{f d-} 4.55 \times 10^{-6} \mathrm{H}$ \\
\hline Direct axis resistance & $R_{k d}(\Omega) \_0.0224 \Omega$. \\
\hline $\begin{array}{l}\text { Direct axis leakage } \\
\text { inductance }\end{array}$ & $L_{k d}-1.4 \times 10^{-3} \mathrm{H}$ \\
\hline Quadrate axis resistance & $R_{k q}(\Omega){ }_{-} 0.02 \Omega$. \\
\hline $\begin{array}{l}\text { Quadrate axis leakage } \\
\text { inductance }\end{array}$ & $L_{k d-} 1 \times 10^{-3} \mathrm{H}$. \\
\hline Inertia coefficient & $\begin{array}{r}J\left(\mathrm{~kg} \cdot \mathrm{m}^{2}\right) \\
24.9 \mathrm{~kg} \cdot \mathrm{m}^{2} \\
\end{array}$ \\
\hline Friction factor & $\begin{array}{r}F(N . m . s e g) \\
\quad 0 N . m . s e g \\
\end{array}$ \\
\hline
\end{tabular}

Zero on all Initial conditions, except on

$$
p h b=120^{\circ}, \quad p h c=240^{\circ}, \quad y \quad V_{f}=5.95
$$

Using the previous parameters for the electric energy generator system formed by synchronous generator, and including tri-phase rectifier, filter, and resistive load (of 400W); simulation with Matlab-Simulink is made for each control strategy in order to compare its performance.

\section{PID CONTROL}

From the classical control theory according with (K. Ogata, 2003; Roland S., 2001, Josep Balcells, 1999, Manfred Schleicher 2004). PID control strategy can be used to design a feedback control. In order to implement this control strategy controller should be tuned; there are several tuning methods, the used here is Ziegler Nichols 2 taken from (K. Ogata, 2003; Roland S., 2001, Josep Balcells, 1999, Manfred Schleicher 2004). In order to be able to apply this method a dynamic test is made to system in open loop condition; to get transfer function and use dominant pole approximation to approach system behavior with a first order with delay system as described on the same references. This means that actual control strategy is a model dependent strategy; this is a lack of classical control theory as parameters change on the systems due to heating. Due to synchronic generators are non-linear devices care must be taken in order to operate it only on certain linear limited range to avoid over voltage and damage on load and generator itself.

Classical control theory and modern control theory (state space) are both model dependent, this makes more difficult to implement these control strategies due that model should be first determined, and then parameter variations compensation introduced on model so that accurate response be obtained. On figure 2 the control scheme for PID control strategy is shown for simulation with Matlab-Simulink. 


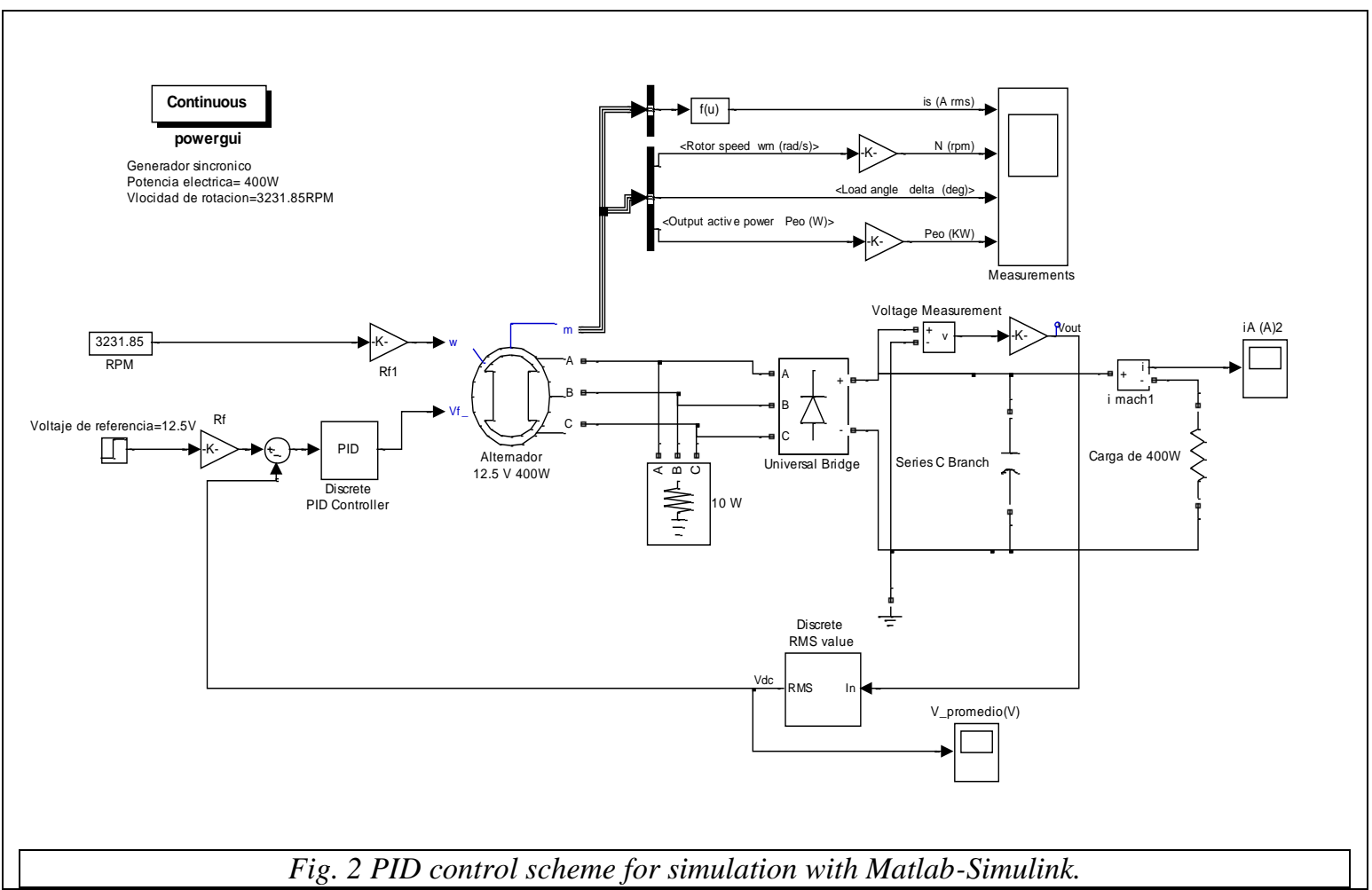

The result of system response simulation for this scheme is shown on figure 3 .

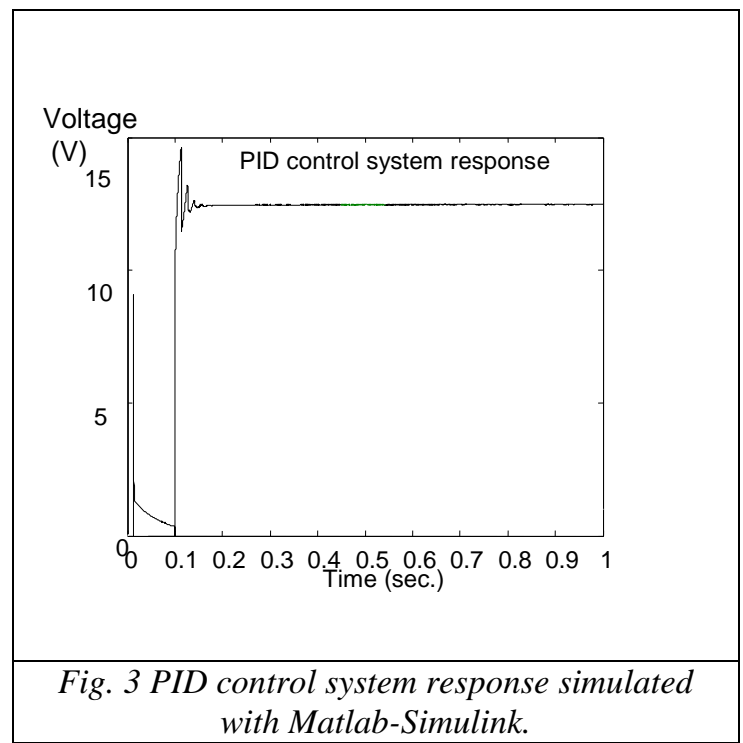

The simulated system is only a portion of the real system due that for simulation proposes is considered only the synchronic generator, filter, rectifier, and load, but the primary motor is disregarded, as well as the mechanical energy transfer device (a belt in this case), get a complete model of the system is a complicated task, instead of that for the real system a dynamical test is made to get an approach model of reduced order knowing that on every system a few poles define the overall response on a system as stated by (K. Ogata, 2003; Roland S., 2001, Josep Balcells, 1999, Manfred Schleicher 2004), respect to the dominant pole principle.

By doing that dynamical test (consisting on the application of a step signal whereas the generator runs at the nominal speed) on the system; a first order model with delay is obtained with the following parameters:

$K_{\text {critical }}=0.395$ Critical gain

$\tau_{\text {critical }}=3.333 \times 10^{-3}$ sec. . First order constant time. And applying the Ziegler Nichols 2 tuning method described on [4,5,6, and 7] for PID controller it results on:

$$
\begin{aligned}
& K_{p}=0.6 K_{\text {critical }}=0.6 \times 0.395=0.237 \\
& \begin{aligned}
T_{i}=0.5 \tau_{\text {critical }}= & 0.6 \times 3.333 \times 10^{-3} \\
= & 1.666 \times 10^{-3}
\end{aligned} \\
& \begin{aligned}
T_{D}=0.125 \tau_{\text {critical }}= & 0.125 \times 3.333 \times 10^{-3} \\
= & 4.166 \times 10^{-4}
\end{aligned}
\end{aligned}
$$


The above values are the parameters need for controller tuning. System response under disturbances on load is as shown on Figure 4.

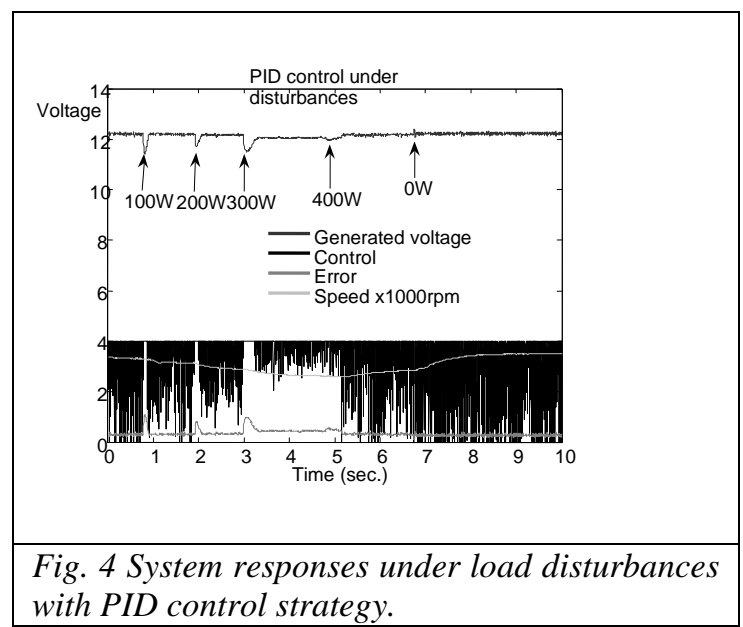

As shown voltage drops for a while when load is increased, then control signal is modified to reduce error.

Depending on the specific application that error could be of interest if a precise control is required. When a system is modeled there are always non modeled dynamics, those are responsible for instability. PID controls require adjusting the controller parameters due to changes on those non modeled dynamics; this is more often if the above mentioned dynamic is exited by heat or wear on system elements. Therefore if a precise control, that be free of adjustments, so another strategy should be considered.

\section{SECOND ORDER SLIDING MODE CONTROL STRATEGIES.}

At (Vadim Utkin, 2008; Bartolini, and Leonid Fridman., 2009, Asif Sabanovic and Leonid M. Fridman, 2004, C. Edwards and E. Fossas 2006, Tsypkin, Yakov, 1984); are introduced two second order sliding modes control strategies named twisting, and super-twisting algorithms.

\subsection{TWISTING algorithm:}

Control scheme for twisting algorithm is recommended at (Vadim Utkin, 2008; Bartolini, and Leonid Fridman., 2009, Asif Sabanovic and Leonid M. Fridman, 2004, C. Edwards and E. Fossas 2006, Tsypkin, Yakov, 1984); and is shown on figure 6.

Where $u(t)=-c_{1} \operatorname{sign}(y)-c_{2} \operatorname{sign}(\dot{y})$, and $c_{1}>c_{2}>0$. This algorithm can be seen as the parallel connection of two ideal relays, the one on top receives sliding variable, and it serves to define if energy should be applied to plant or not, depending on actual value of that variable (that value depends on the difference between the reference value, and output voltage ). The relay on bottom is placed to determine the direction and change ratio on sliding variable. As stated (Vadim Utkin, 2008; Bartolini, and Leonid Fridman., 2009, Asif Sabanovic and Leonid M. Fridman, 2004, C. Edwards and E. Fossas 2006, Tsypkin, Yakov, 1984); $c_{1}$ and $c_{2}$ values can be selected the way finite time stability be achieved on finite time, by analogy with relay type control, and considering the extreme case where $c_{2} \rightarrow 0$. It makes this scheme equal to a relay control where $c_{1}$ can have only two values $5 \mathrm{~V}$, and $0 \mathrm{~V}$ so that synchronic generator be on saturation, and cut states respectively whereas it runs at nominal speed, those $5 \mathrm{~V}$ are specific for this particular case because it was observed that running at mentioned speed, and applying $5 \mathrm{~V}$ to actuator, field current will not produce an output voltage that will damage load, and generator, so this is more a design parameter than a variable to calculate, and depends on the specific application. Twisting algorithm should produce a second order oscillation, and therefore $0 \mathrm{~V}<c_{2}<c_{1}=5 \mathrm{~V}$, so after testing a few values on that range second order oscillation appears at $0 \mathrm{~V}<c_{2}<0.9 \mathrm{~V}$. Figure 7 shows simulation results for those values.

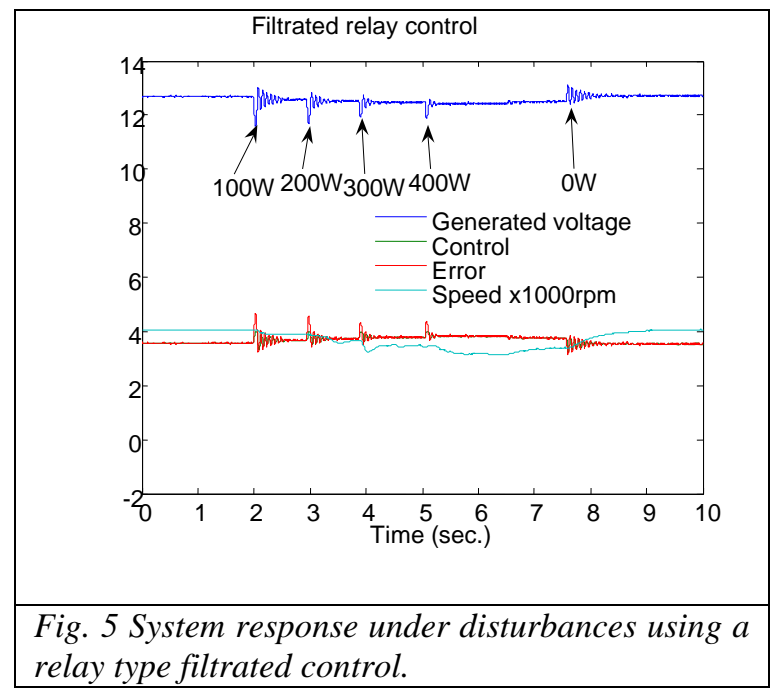



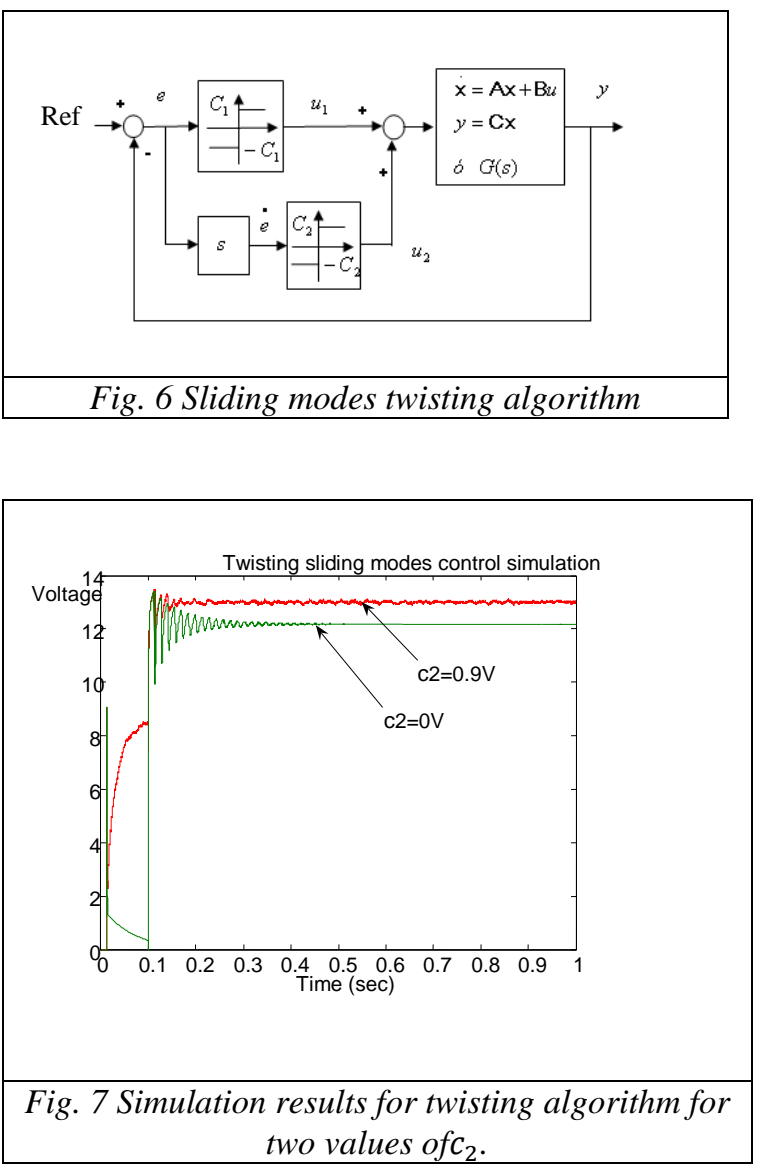

As it's stated that $c_{2}>0, c_{2}=0.9$ is used and second order damped signal produced with that value is found to be described as stated on (K. Ogata, 2003; Roland S., 2001, Josep Balcells, 1999, Manfred Schleicher 2004) by:

$t_{p}=0.01296 \mathrm{sec}$

$\omega_{d}=\frac{\pi}{t_{p}}=\frac{\pi}{0.01296}=242.3514 \mathrm{Rad} / \mathrm{sec}$

$t_{s}(5 \%)=0.2 \mathrm{seg}$

$\sigma=\frac{3}{t_{s}}=\frac{3}{0.2}=15$

$\zeta=\sqrt{\frac{1}{262.0408}}=0.061775$

$\omega_{n}=\frac{\sigma}{\zeta}=\frac{15}{0.061775}=242.8151 \mathrm{rad} / \mathrm{seg}$

$\therefore G\left(s=\frac{(242.8151)^{2}}{s^{2}+2(0.061775)(242.8151) s+(242.8151)^{2}}\right.$
Using Matlab, Nyquist graph can be found with command nyquist(num,den). Figure 8 shows Nyquist graph for the above second order transfer function.

With chattering frequency given as $\Omega=70 \mathrm{~Hz}=$ $439.8 \mathrm{rad} / \mathrm{seg}$ on figure 14 can be located the values Real $=-0.456$ and Imag=0.0462, knowing that $\operatorname{arcTg}\left(c_{2} / c_{1}\right)=\alpha$, and $\operatorname{Tan}(\alpha)=\frac{I m}{R e=\frac{0.0462}{0.456}=0.101315}$

$$
\begin{aligned}
& \therefore \alpha=\arctan (0.101315)=5.7852^{\circ}= \\
& \arctan \frac{c_{2}}{c_{1}} \text { where }
\end{aligned}
$$

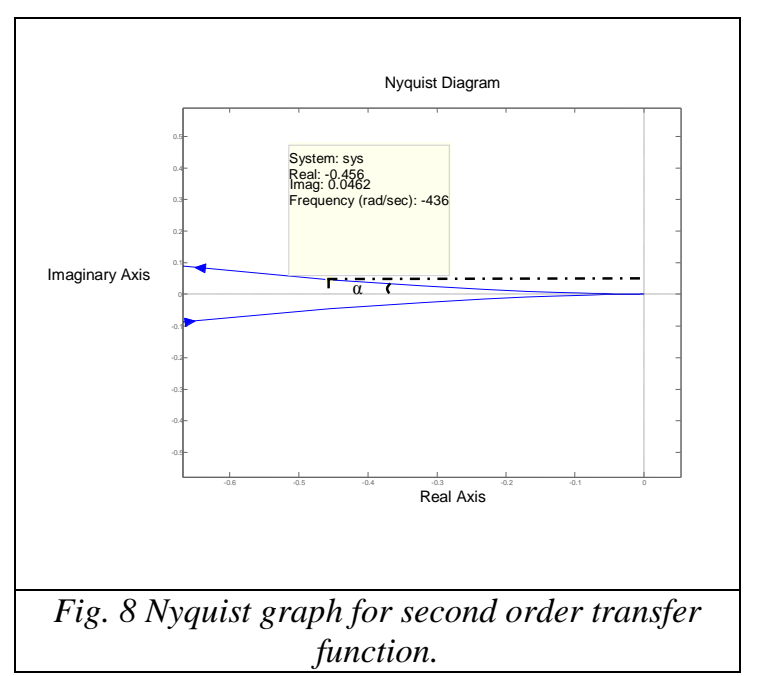

where $c_{2}=c_{1} \operatorname{Tan}(\alpha)=5 \operatorname{Tan}\left(5.7852^{\circ}\right)=0.506 \mathrm{~V}$, once re-adjusted $c_{2}$ new system response is shown on figure 9 .

With a similar procedure, applied to synchronic generator, system parameters are determined; system response subject to disturbances on load is shown on figure 16.

It can be seen that this control strategy is more robust than the others exposed at this point, it's chattering free and disturbances on load are completely eliminated thanks to the prediction introduced by second ideal relay dealing with error derivative. 

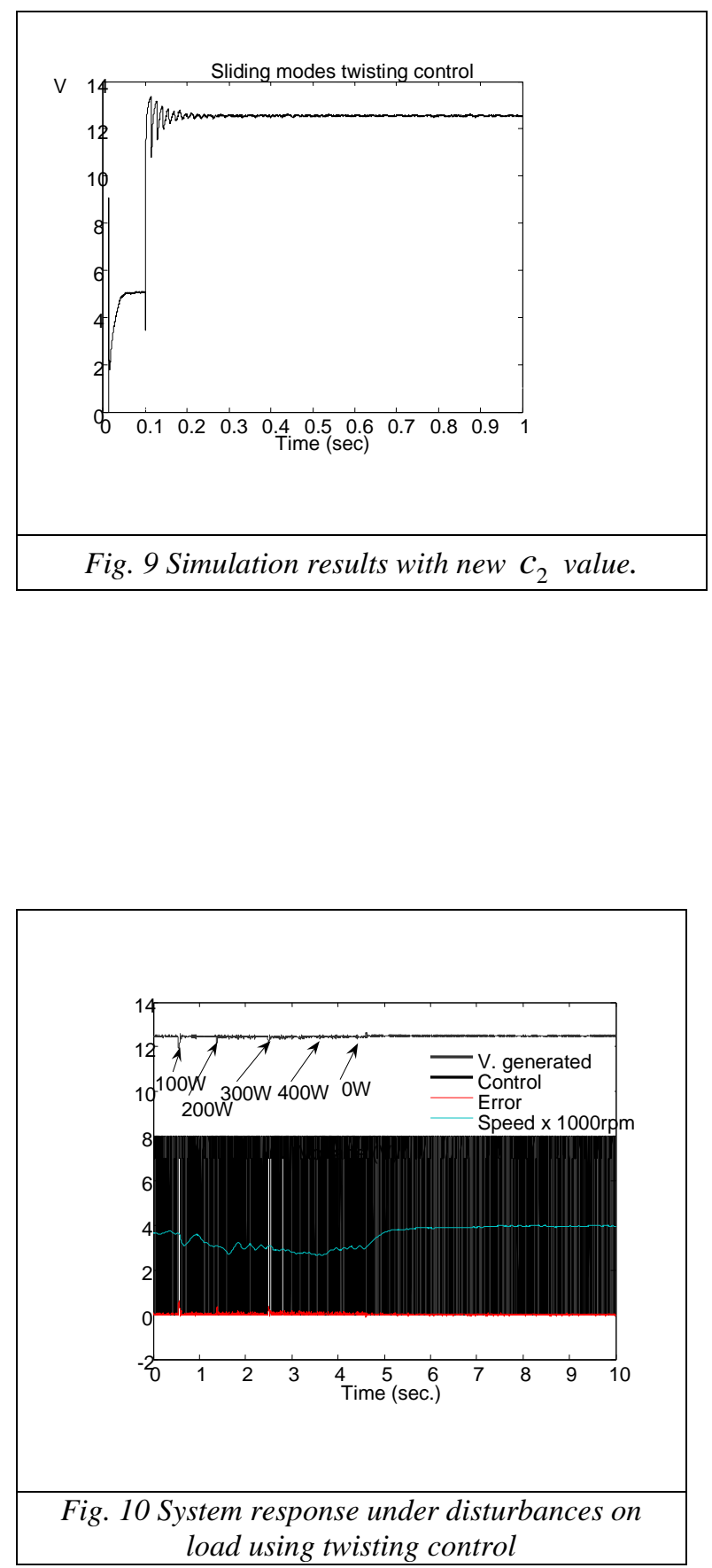

\subsection{SUPER-TWISTING}

As stated on (Vadim Utkin, 2008; Bartolini, and Leonid Fridman., 2009, Asif Sabanovic and Leonid M. Fridman, 2004, C. Edwards and E. Fossas 2006, Tsypkin, Yakov, 1984); this control algorithm is also a second order resource that warranties chattering elimination at the same time that keeps a highly robust control strategy. Same as the previous is free of model, and parameter variation, it's main characteristic is a continuous control signal which avoids non modeled dynamics on sensors, and actuators to be excited. In order to implement this strategy, twisting algorithm, and both relay type strategies; controller speed should be at least 10 times faster than the fastest plant dynamic. A few years ago this was a limitation to implement the above mentioned strategies, however currently high processing speed on controllers allows it. As mentioned on the references theory for relay type controllers exists at least since 1950's, but semiconductor technology has recently had improved computation speed which is essential for those control strategies.

Super -twisting control strategy is described on (Vadim Utkin, 2008; Bartolini, and Leonid Fridman., 2009, Asif Sabanovic and Leonid M. Fridman, 2004, C. Edwards and E. Fossas 2006, Tsypkin, Yakov, 1984); and shown on figure 11.

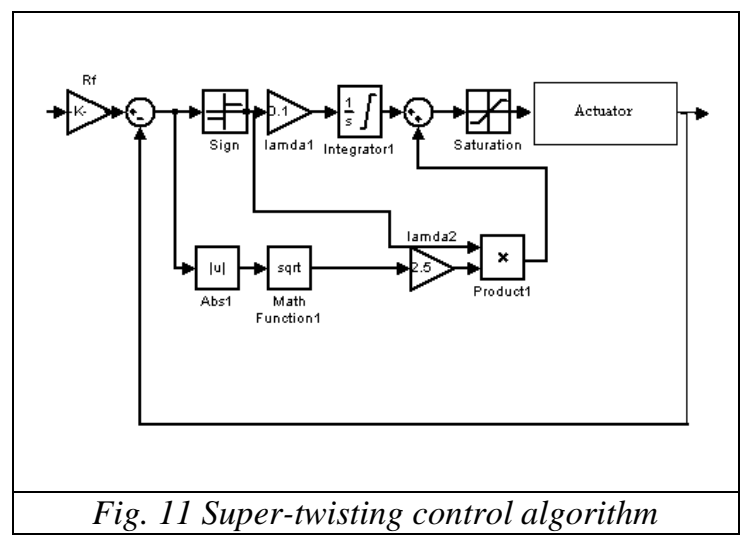

This scheme is formed by two paths both converging at the sum point. The propose of path on top is to identify if the actual condition on error signal, on physical terms determine if energy should be applied or removed form plant via actuator. On that path $\lambda_{1}$ is a parameter that weighs up error value. With this a minimum adjusting resolution is established for control signal, then integrator acts as accumulator calculating the algebraic sum between actual error, and previous valor, this way each time algorithm iterates control signal value is adjusted. Therefore $\lambda_{1}$ value, should be selected so that adjusting step be soft enough on each program iteration to avoid chattering. At the same time 
if $\lambda_{1}$ is selected very small a lot of program cycles will be required and this will lack algorithm robustness.

For path on bottom square root of absolute value on error signal is weigh up by $\lambda_{2}$ parameter, with this a minimum resolution is also defined on adjusting steps. By the superposition effect on sum point there are two signals used to constitute control signal, both are adjusted with different weighted steps, path on top with soft steps, and path on bottom with abrupt steps in order to reduce the amount of iterations (time) to get expected output value. For this reason sliding mode control is part of variable structure systems.

As seen parameters $\lambda_{1}$ and $\lambda_{2}$ are dependent on desired resolution, actuator characteristics, and free of plant model. Therefore plant parameter variations have no effect. In order to determine $\lambda_{1}$ and $\lambda_{2}$ saturation voltage required by actuator need to be determined, this is an easy task and is dependent on particular application, for this case is of about $4 \mathrm{~V}$ as shown on figure 11. It was mentioned that $\lambda_{1}$ is defined for soft adjustments, so if $\lambda_{1}=0.1 \mathrm{Vit}$ 's necessary on worst case scenario to have $4 \mathrm{~V} / 0.1 \mathrm{~V}=40$ program cycles, but as iteration time takes $0.0005 \mathrm{sec}$, going from 0 to $4 \mathrm{~V}$ takes only $40 \times 0.0005 \mathrm{sec} .=0.02 \mathrm{sec}$, if path on bottom doesn't have effect. When control system reaches steady state, path on bottom is disabled, and adjustments on control signal are made with 0.1 resolution in this case, that means path on bottom is used to provide robustness to deal with disturbances, but once those are surpassed this path effect is reduced remaining only effect of top path. With this control signal is both a combination of continuous and discontinuous signal.

In order to determine value for $\lambda_{2}$, a few test values can be used considering zero initial conditions, and reasonable output voltages, for example if output voltage is zero error signal is $12.5 \mathrm{~V}$, this means that at integrator the value is defined by acum $+\lambda_{1}$ (top path) at the same time at the end of bottom path (sum point) value is defined by $3.53 \lambda_{2}$, therefore sum output value is acum $+\lambda_{1}+3.53 \lambda_{2}$, but as initial conditions are zero it's reduced to $\lambda_{1}+3.53 \lambda_{2}$, on the same sense if output voltage is $1 \mathrm{~V}$ the result will be $\lambda_{1}+3.39 \lambda_{2}$, for $6.0 \mathrm{~V}$, is $\lambda_{1}+2.54 \lambda_{2}$, for $12.5 \mathrm{~V}$ is 0 , for $14.0 \mathrm{~V}$ is $-\lambda_{1}-1.41 \lambda_{2}$, and for $18.0 \mathrm{~V}$ the result is $-\lambda_{1}-$ $2.34 \lambda_{2}$. Therefore the maximum positive value that can be on actuator is given by $\lambda_{1}+3.53 \lambda_{2} \leq 4.0 \mathrm{~V}$, and the minimum value is zero due that applying $0 \mathrm{~V}$ on MOSFET gate used as actuator it's output is zero, discarding negative values which produces the same null output.

Then substituting $\lambda_{1}=0.1$ in $\lambda_{1}+3.53 \lambda_{2} \leq 4.0$, and resolving we have $\lambda_{2} \leq 1.10$. So testing a few values in range $0 \leq \lambda_{2} \leq 1.10$ the observed value that gives a better result on simulation is $\lambda_{2}=0.5$, results are shown on figure 12 .

Following the above mentioned procedure for tuning controller, and subjecting system to load disturbances, it's response is as shown on figure 13 .
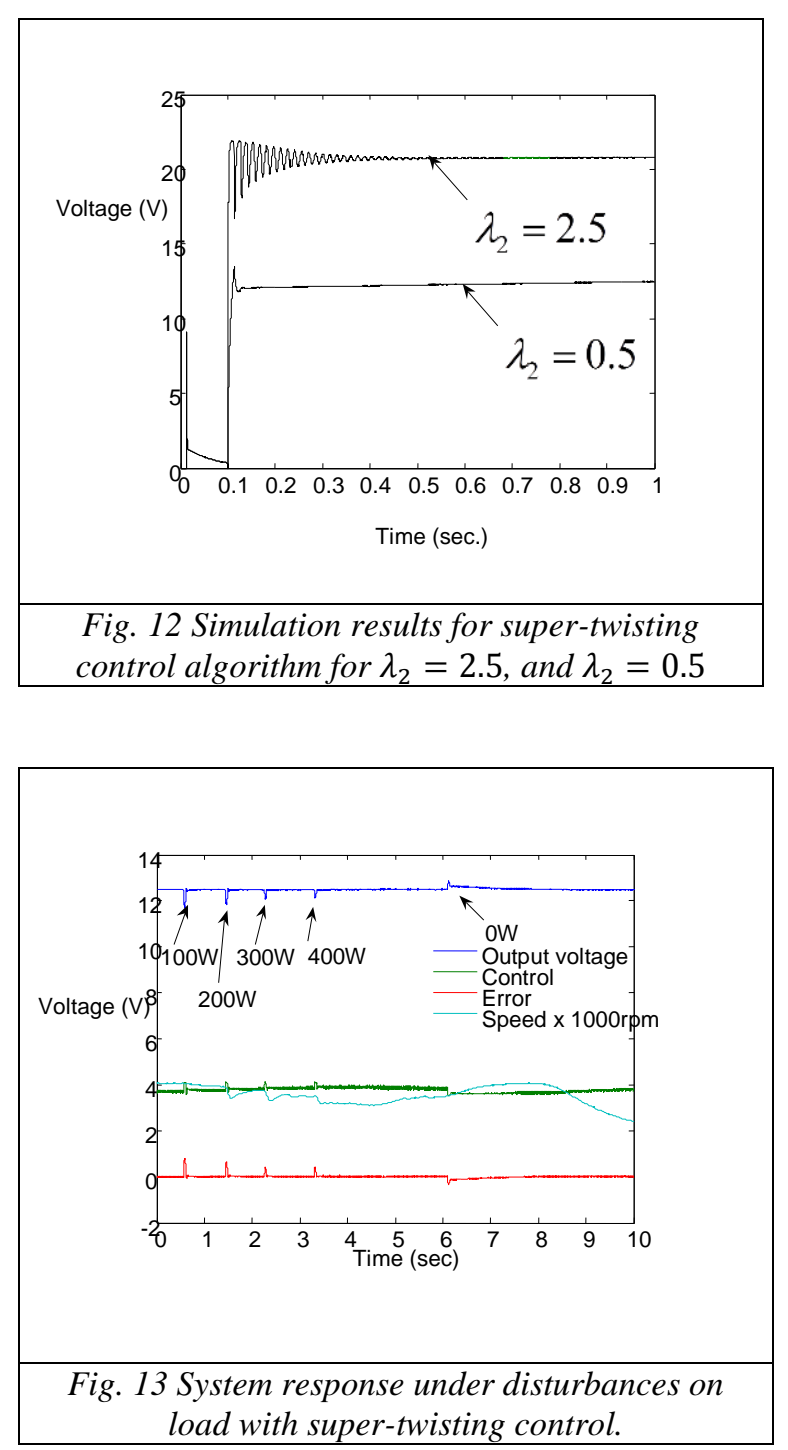

It can be seen that control signal is now a continuous signal, output voltage is chattering free, and system robustness is achieved due that disturbances on load are essentially eliminated.

On figure 14 are shown the different system responses when load disturbances are applied and the effect of those on the different control strategies seen on this document. 


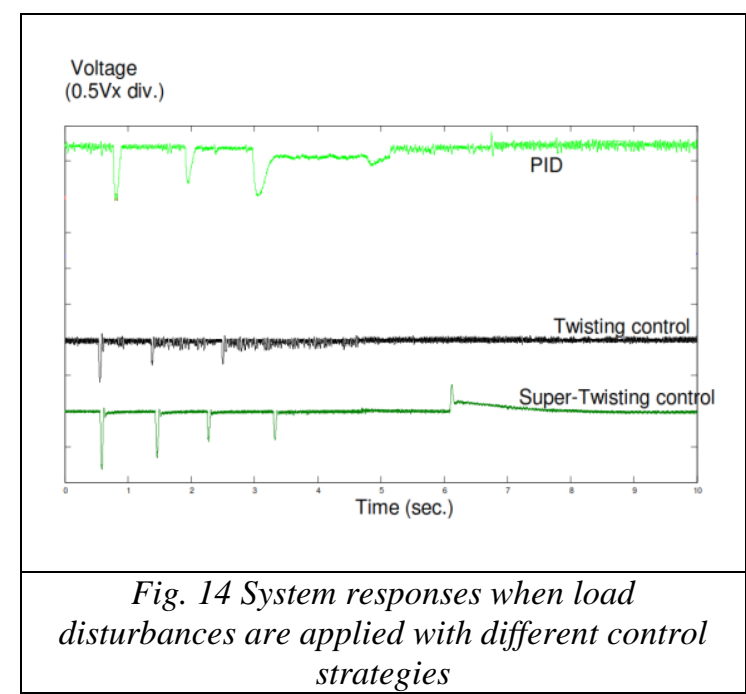

\section{CONCLUSIONS}

Second order sliding mode control strategies are a superior control tool; robustness, system model free, chattering free, easy to implementation, adjusting by system parameter change due to heat, and wear free; are the main advantages over classic type control strategies.

In order to implement second order sliding modes strategies, high speed controllers must be used. With technology advances on microelectronics field, now this is feasible even since 1950's sliding modes theory exists. So a new powerful tool is now available for use on different application fields.

Bibliography:

Stephen J. Chapman, Máquinas eléctricas, $2^{a}$ edición, ed McGraw-Hill, Mayo 1996, México.

Salvador Campos Hernández. Determinación de los Parámetros Eléctricos de las Máquinas Síncronas en Función de la Frecuencia "Tesis para obtener el grado de Maestro en Ciencias en Ingeniería Eléctrica por El Instituto Politécnico Nacional" A 5 de Agosto de 2005, México.

H.Bora Karayaka, Ali Keyhani IEEE TRANSACTIONS ON ENERGY, VOL 18, NO. 1 MARCH 2003 "Synchronous Generator Model Identification and Parameter Estimation From Operating Data", Fellow IEEE, Gerald Thomas Heydt, Fellow, IEEE, Baj L. Agrawal, Fellow,
IEEE, and Douglas A. Selin, Senior Member, IEEE, USA.

K. Ogata. Ingeniería de control moderna, $4^{a}$ edición, ed PEARSON Prentice Hall, 2003, España.

Roland S. Burns. Advanced Control Engineering, $1^{\text {st }}$ edition, ED. Butterworth Heinemann, 2001, UK.

José Luis Romeral. Autómatas programables Josep Balcells, , $1^{\text {a }}$ edición, ED Alfaomega marcombo, 1999, México.

Manfred Schleicher, Frank Blasinger. Control Engineering A guide for beginners Ed JUMO GMBH \& Co. KG , Fulda, Germany 3rd Edition 2004, Germany.

Vadim Utkin, Jurgen Guldner and Jingxin Shi Sliding. Mode Control in Electromechanical Systems CRC PRESS, USA.

Giorgio Bartolini, Leonid Fridman. Modern Sliding Mode Control Theory New Perspectives and Applications, Alessandro Pisano, Ed Springer, 2008, Germany.

Leonid M. Fridman, and Sarha Spurgeon Variable Structure Systems from principles to implementation, Asif Sabanovic, Leonid M.

Fridman, and Sarha Spurgeon, $1^{\text {st }}$ edition, British Library Cataloguing in Publication data, 2004, UK.

C. Edwards, E. Fossas Colet., L. Fridman Advances in Variable Structure and Sliding Mode Control, Ed. Springer, 2006, Germany.

Tsypkin, Yakov Z. Relay Control Systems, Cambridge Univ Press, 1984, UK. 